ASPECTOS AMBIENTALES REGULAdOS EN LOS RECIENTES TRATAdOS D.

LIBRE COMERCIO, CON ESPECIAL REFERENCIA AL TRATADO DE Asociación Trans-Pacífico (TPP)

\author{
Rafael J. Pérez Miranda \\ UniverSidAd AutónOMa de MÉXICO - AzCAPOTZalco \\ FACULTAD DE DERECHO - UBA \\ CONACYT - MÉXICO
}

ÍNDICE TEMÁTICO

1. Hacia una nueva Organización Mundial del Comercio 1.1. La APLICACIÓN NACIONAL DEL NUEVO DERECHO ECONÓMICO INTERNACIONAL 1.2. LAS NEGOCIACIONES PARALELAS SOBRE MEDIO AMBIENTE Y DERECHOS HUMANOS 2. UNA NEGOCIACIÓN SECRETA 3. RELACIÓN CON OTROS TRATADOS INTERNACIONALES Y LA Cláusula de Nación Más Favorecida 4. Compromiso de Adherir a Tratados INTERNACIONALES DE LOS CUALES LOS PAÍSES PARTES NO SEAN PARTE. 5. ASPECTOS ReleVantes Del CAPÍtulo sobre Medio Ambiente 5.1. Contenido del CAPÍtulo AMbiental 5.2. Protección de la DiVERsidad BiolóGiCA, ReCuRsos GenÉticos 5.3. Bioseguridad de los Organismos Vivos Modificados Genéticamente 5.4. Medio AMBIENTE E INVERSIÓN EXTRANJERA 5.6. MEDIO AMBIENTE y PROPIEDAD INTELECT Vegetales y ANimales 6. Algunas conClusiones. REFERENCIAS BibliogRÁFiCAS. 


\section{ASPECTOS AMBIENTALES REGULADOS EN LOS RECIENTES TRATADOS DE LIBRE COMERCIO, CON ESPECIAL REFERENCIA AL TRATADO DE ASOCIACIÓN TRANS-PACÍfiCo (TPP)}

\section{RESUMEN}

Estados Unidos y la Unión Europea están negociando tratados de libre comercio destinados a consolidar el proceso de apertura comercial, de ampliación de la materia patentable y de las obras protegidas, así como la protección de las inversiones extranjeras. La presión de la sociedad civil originó la inserción de capítulos sociales relacionados con la materia ambiental y laboral. En este ensayo se analiza en especial el capítulo ambiental del Tratado de Cooperación Trans Pacífico, que es un avance en la medida que se reconoce que los estímulos a la inversión están supeditados a la protección del medio ambiente; sin embargo, este capítulo no ofrece instrumentos jurídicos que garanticen estos avances meramente teóricos.

\section{Hacia una nueva Organización Mundial del Comercio}

El Tratado de Marrakech cristalizó el proyecto de Derecho Económico Internacional más ambicioso de las últimas décadas; creó la Organización Mundial del Comercio (OMC), que moderniza el Acuerdo General sobre Aranceles y Comercio (GATT); para integrarse a este sistema moderno de liberalización comercial los países deben adherir obligatoriamente a un conjunto de Acuerdos a él vinculados, entre los que destacan los relacionados con servicios, propiedad industrial, agricultura, cuestiones fitosanitarias, inversión. ${ }^{1}$ Para avanzar en nuevas regulaciones se sostuvo el sistema de "rondas" que había permitido progresos en los años de vigencia del GATT. ${ }^{2}$ Es a través de la primera ronda, la Ronda de Doha, que se propuso la OMC satisfacer reclamos

\footnotetext{
${ }^{1}$ Acuerdo de Marrakech por el que se establece la Organización Mundial de Comercio (OMC); la OMC y los Acuerdos aludidos cobraron vigencia el $1^{\circ}$ de enero de 1995.

${ }^{2}$ El tratado de Marrakech es producto, precisamente, de una de esas rondas, la Ronda Uruguay.
} 
pendientes de los países en desarrollo y más pobres respecto a las subvenciones de los países industrializados al sector agrícola ganadero y aspectos pendientes en materia ambiental y de propiedad intelectual. Sin embargo, a más de 20 años de vigencia del Tratado no se han logrado avances significativos, y si bien se anuncian progresos en cada una de las múltiples reuniones, las negociaciones se encuentran paralizadas en los aspectos sustantivos debido a las posiciones antagónicas entre los países en desarrollo y los países industrializados, los cuales por otra parte tienen también contradicciones a su interior.

Una alternativa a la parálisis ha sido impulsar acuerdos regionales, tratados de libre comercio, y sectoriales, tratados de promoción y protección de la inversión extranjera, en los cuales los países en desarrollo negocian separados o en pequeños grupos y se ven obligados a aceptar las imposiciones de los países industrializados. A los múltiples tratados de libre comercio y de protección de la inversión extranjera entre países industrializados y países en desarrollo se agregan en estos momentos tratados como el celebrado por la Unión Europea con Canadá (CETA, por su sigla en inglés), el Tratado de Asociación Trans - Pacífico (TPP) celebrado por Estados Unidos, Japón, Canadá y Australia con México, Perú, Chile, Singapur, Vietnam, Brunei, Malasia y Nueva Zelandia y el Tratado de Libre Comercio e Inversión que están negociando Estados Unidos (USA) y la Unión Europea (TTIP, por su sigla en inglés). En todos ellos se incluyen, además de regulaciones específicas sobre comercio de mercancías y servicios, capítulos sobre propiedad intelectual, protección de inversiones, así como referencias a cuestiones ambientales y de derechos humanos. Es clara, por otra parte, la participación no oficial pero activa y eficiente, en las negociaciones, de las grandes corporaciones transnacionales interesadas en facilitar la integración de sus cadenas productivas y en aprovechar al máximo las utilidades derivadas de su mayor capacidad 


\section{ASPECTOS AMBIENTALES REgUlados EN LOS RECIENTES Tratados DE LIBRE COMERCIO, CON ESPECIAL REFERENCIA AL TRATADO DE ASOCIACIÓN TRANS-PACífiCO (TPP)}

tecnológica y de su posición oligopólica en la oferta y demanda internacional y en la mayoría de los mercados nacionales.

Los avances coincidentes en los puntos sustantivos que se negocian en estos tratados orientarán en un futuro próximo, sin duda, las características del nuevo Derecho Económico Internacional, con disposiciones que sistematizarán aquellas que los países en desarrollo han logrado bloquear, hasta ahora, en las negociaciones multilaterales con vocación universal como las rondas de la OMC. Es decir, se está diseñando aceleradamente un Nuevo Orden Económico Internacional acorde a los intereses de las grandes corporaciones internacionales y de las grandes potencias. Parte de este proceso se vincula a la disputa con las poderosas economías emergentes, los denominados BRICS, China en especial, que diseña por su parte una serie de alianzas mercantiles y de inversión, en ciertos casos con los mismos países que las celebran con EUA, la Unión Europea y Japón.

\subsection{LA APLICACIÓN NACIONAL DEL NUEVO DERECHO ECONÓMICO INTERNACIONAL}

El nuevo Derecho Económico Internacional ha demostrado en las últimas décadas una capacidad importante para lograr que se respeten los acuerdos y cuando consisten en adecuaciones legislativas, las mismas se realicen. Han contribuido en el logro de esta eficiencia, de esta neocoercibilidad del derecho internacional, la modernización del sistema de solución de diferencias entre países partes de la OMC y el establecimiento de un sistema de solución de diferencias entre particulares y estados en materia de inversión extranjera, que gira alrededor del Centro Internacional de Arreglos de Diferencias en materia de Inversiones (CIADI), en las relaciones entre países partes y entre inversores y países partes respectivamente. A ello se debe agregar la tendencia, en el derecho constitucional moderno, de incorporar disposiciones que de manera expresa 
reconocen la preeminencia jerárquica de los tratados internacionales sobre la legislación nacional.

Es decir, a la costumbre internacional tradicional de cumplir los acuerdos internacionales con base en el principio Pacta SuntServanda, hoy debemos agregar un diseño de sistemas de control en cada tratado con sanciones comerciales o económicas que presionan eficientemente para su cumplimiento y un sistema de derecho interno que mediante el control de convencionalidad permite a los particulares recurrir directamente al derecho internacional para la solución de sus conflictos recurriendo a su preeminencia sobre el derecho nacional. ${ }^{3}$

\subsection{LAS NEgOCIACIONES PARALELAS SOBRE MEDIO AMBIENTE Y DERECHOS} HUMANOS

En paralelo a los tratados internacionales de libre comercio, continúan intensas negociaciones sobre temas ambientales y de derechos humanos que, paradójicamente, los contradicen en muchos temas nodales. Así, los limitados avances en convenciones como el Protocolo de Nagoya de la Convención de Diversidad Biológica, o los acuerdos para avanzar en un régimen jurídico eficiente sobre los recursos genéticos oceánicos en zonas que se encuentran fuera de las jurisdicciones nacionales son ignorados en los acuerdos sobre libre comercio e inversión, en especial por cuanto EUA no es parte de la Convención sobre Diversidad Biológica (CDB) ni de la Convención de Naciones Unidas sobre Derecho del Mar (CONVEMAR), pues considera que afectan su

\footnotetext{
${ }^{3}$ Ver sobre estos aspectos Becerra Ramírez, M. (2013). El control de la aplicación del derecho internacional. En el marco del Estado de derecho. México: Ed. Universidad Nacional Autónoma de México. Instituto de Investigaciones Jurídicas.
} 


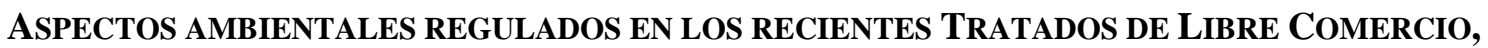 CON ESPECIAL REFERENCIA AL TRATADO DE ASOCIACIÓN TRANS-PACífiCO (TPP)}

competitividad internacional. ${ }^{4}$ Tampoco es parte EUA de los tratados internacionales sobre Derechos Humanos denominados de segunda generación, por lo cual en los tratados de libre comercio se evita el intenso debate doctrinal sobre derechos humanos a la salud y derechos de propiedad industrial o sobre los derechos humanos de acceso a la educación y a la cultura y los derechos de propiedad intelectual, derechos de autor. Es más, exige que no se inserte en ningún acuerdo el término "derecho humanos"

El resultado de estas negociaciones paralelas pero dispares se traduce en una mayor eficiencia y coercibilidad de los tratados internacionales crematísticos respecto a los relacionados con aspectos sociales y ambientales.

\section{UNA NEGOCIACIÓN SECRETA}

A partir del inicio de la negociación del Acuerdo Comercial Antifalsificación (ACTA), se han iniciado nuevas negociaciones de tratados internacionales con características similares, nos referimos en especial a la confidencialidad del proceso hasta su firma, que implica inclusive la ignorancia por parte de los legisladores, y del conjunto de la ciudadanía, de los términos precisos de los temas que se negocian. Múltiples son los argumentos utilizados para justificarlo: que es necesario evitar presiones de la sociedad civil, evitar presiones a y de los partidos políticos, evitar que la sociedad en general, que no conoce los aspectos técnicos de estas negociaciones y que ignora las ventajas que se pueden derivar de ellas, sea influenciada por opiniones interesadas, o que se centre la crítica en aquellos aspectos negativos de un acuerdo que en su conjunto será altamente positivo.

\footnotetext{
${ }^{4}$ Protocolo de Nagoya sobre Acceso a los Recursos Genéticos y Participación Justa y Equitativa en los beneficios que se deriven de su utilización al Convenio sobre la Diversidad Biológica. Convención de Naciones Unidas sobre Derecho del Mar (CONVEMAR).
} 
Con esta característica de confidencialidad, se está negociando en este momento un Tratado de Libre Comercio e Inversión entre los Estados Unidos de América y la Unión Europea, la Asociación Transatlántica de Comercio e Inversión (TTIP) y acaba de finalizar la negociación del Tratado de Asociación Trans - Pacífico (TPP). ${ }^{5}$ No menos importante ha sido la celebración del Tratado de Libre Comercio entre Canadá y la Unión Europea (CETA). Sin embargo han sido diferentes las reglas de confidencialidad de las negociaciones del TPP respecto de las que se realizan entre los Estados Unidos de América y la Unión Europea; efectivamente, el Parlamento de la Unión Europea rechazó el tratado internacional ACTA porque los legisladores consideraron que se habían violado las normas comunitarias al discutir y aprobar el tratado sin informar periódicamente sobre los avances de la negociación. Con este antecedente, la sociedad civil de la Unión Europea presionó para evitar que se repitiera este fenómeno y logró que se hicieran públicas las instrucciones que se entregaron a los negociadores; en realidad logró que se hiciera pública una parte muy general de estas instrucciones, insuficientes para conocer con precisión el avance de las negociaciones pero suficiente para conocer al menos las líneas generales en disputa. ${ }^{6}$ En un tema relevante, el de la protección de las inversiones, estas instrucciones se pueden vincular con las políticas diseñadas en noviembre de 2013 que en cierta medida se aplicaron en el Tratado de Libre Comercio Unión Europea / Canadá. ${ }^{7}$

México repitió la experiencia del Tratado de Libre Comercio para América del Norte, durante cuya negociación estableció lo que se denominó "el cuarto de al lado";

\footnotetext{
${ }^{5}$ El Tratado ya fue firmado por los Países Partes y debe ser sometido a la aprobación y ratificación por cada uno de ellos.

${ }^{6}$ Council of the European Union.Directives for the negotiation on the Transatlantic Trade and Investment Partnership between the European Union and the United States of America.Brussels, 9 October 2014.

${ }^{7}$ Ver: Consolidated CETA Text, Publishedon 26 September 2014.
} 


\section{ASPECTOS AMBIENTALES REgUlAdOS EN LOS RECIENTES TrATADOS DE LIBRE COMERCIO, CON ESPECIAL REFERENCIA AL TRATADO DE ASOCIACIÓN TRANS-PACÍFICO (TPP)}

éste consistía en representantes del sector privado que acompañaban a los negociadores gubernamentales como "asesores" que no participaban de las reuniones confidenciales pero eran informados y emitían sus opiniones desde "el cuarto de al lado"; esta estrategia presenta varios obstáculos, entre ellos que sólo se invita a representantes seleccionados del sector empresarial, no a representantes sindicales ni a organismos no gubernamentales, por una parte y que se trasmite información muy general y limitada, por otra. Un punto a considerar es que en estos tratados no se aceptan modificaciones ni reservas más allá de las negociadas y firmadas antes de que se presenten a los congresos o parlamentos para su ratificación, por lo cual se agravan los efectos nocivos de la secrecía, llegando a cuestionar la independencia de los poderes. En efecto, los legisladores son puestos frente a la alternativa de aprobar o rechazar en su conjunto un Convenio Internacional; si consideran que el balance es positivo se verán obligados a aprobarlo a libro cerrado, lo cual los obligará a posteriori a reformar aspectos importante de la legislación para que se adecúe a él, sin tener la posibilidad de decidir qué partes consideran positivas para el país y cuales no.

Los Convenios descritos, siguiendo y profundizando la metodología adoptada por el Tratado de Marrakech, contienen un temario que excede en mucho el intercambio internacional de mercancías y servicios, atentos a las necesidades de la integración y sistematización de las cadenas de producción de las grandes corporaciones internacionales; destacan en el TPP los capítulos relacionados con el Derecho Económico Internacional de las Inversiones, de la Propiedad Intelectual, del Medio Ambiente y con ciertos aspectos del derecho de la competencia y del derecho laboral, sin que se haya explicitado con claridad, como se expuso, el motivo de su inclusión en un Tratado de Libre Comercio. 


\section{Relación CON Otros Tratados Internacionales y la Cláusula de NaCión}

\section{Más FAvorecida}

De los países partes del TPP, México tiene un Tratado de Promoción y Protección de la Inversión Extranjera con Australia y Tratados de Libre Comercio con EUA, Canadá, Perú, Chile, Singapur y Japón; en todos ellos se incluye un capítulo sobre protección de las inversiones y sobre propiedad intelectual; en el Tratado de Libre Comercio para América del Norte (TLCAN), se aprobaron Acuerdos Paralelos sobre temas laborales y ambientales, que se agregaron a posteriori de una primera aprobación y que no tienen la fuerza de los restantes capítulos ya que sólo permiten sanciones económicas (no comerciales) en caso de incumplimiento. En todos, además, se incluyó la Cláusula de Nación Más Favorecida tanto en el texto general como una versión especial en cada capítulo sobre inversión y propiedad intelectual. A ello se debe agregar que México, Perú y Chile son parte, junto a Colombia, de la Alianza del Pacífico, que en su Protocolo Adicional tiene un capítulo sobre Inversiones. Es decir, las relaciones jurídicas los inversores de Perú, Chile y México que invirtieran en uno de estos países que no fuera el suyo están sujetos a las normas jurídicas sobre el mismo tema del país en el que realizaron la inversión y de los capítulos sobre inversión de tres Tratados Internacionales de Libre Comercio. El inversor, en consecuencia y según lo dispuesto en los tratados, puede optar por cualesquiera de los cuerpos normativos citados, con mayor o menor amplitud según la interpretación de los árbitros de cada caso. Así, por ejemplo, un peruano que invirtiera en México puede optar por recurrir a los tribunales mexicanos y a las normas mexicanas sobre expropiación, o a los sistemas arbitrales establecidos en 


\section{ASPECTOS AMBIENTALES REgUlados EN LOS RECIENTES Tratados DE LIBRE COMERCIO, CON ESPECIAL REFERENCIA AL TRATADO DE ASOCIACIÓN TRANS-PACífiCO (TPP)}

los sistemas de se solución de controversias en materia de inversión de cualquiera de los tres tratados citados. ${ }^{8}$

Consideramos que estas cláusulas pueden generar dificultades serias en las materias en estudio, pero serán más importantes en los casos en que los mismos temas son regulados, además, en tratados suscritos con los mismos países; el caso más delicado es, aparentemente, el de la protección de las inversiones.

El TPP establece en su primer capítulo algunas disposiciones respecto a las relaciones con otros tratados. En términos generales dice que las partes deberán cumplir con lo acordado "tanto en este tratado como los restantes tratados internacionales que hubieran suscrito".

Ahora bien, para el caso en que una de las partes considerara que lo acordado en el TPP se contradice con una disposición de otro tratado en el cual también sea parte un país miembro del TPP, los Países Partes realizarán consultas para tratar de alcanzar una solución mutuamente satisfactoria; dejando a salvo la posibilidad de recurrir al capítulo 28.

El capítulo sobre protección del inversión extranjera establece en su artículo 9.5 el principio el trato de nación más favorecida, y de su lectura es claro que en caso de haber varias disposiciones sobre un mismo tema será el inversionista quien elija, quien decida, que se aplique aquella disposición que más lo favorece, no el Trato más

\footnotetext{
${ }^{8}$ Acuerdo entre el Gobierno de los Estados Unidos Mexicanos y el Gobierno de Australia para la Promoción y Protección Recíproca de las Inversiones. Cobró vigencia a partir del 21/07/2007, con una vigencia por 10 años prorrogables por tiempo indefinido. Tratado de Libre Comercio entre la República de Chile y los Estados Unidos Mexicanos. Vigencia indefinida. Entrada en vigor: 01/08/1999. Inversión, Capítulo 9. Propiedad Intelectual Cap. 15. Acuerdo para el Fortalecimiento de la Asociación Económica entre los Estados Unidos Mexicanos y el Japón; entrada en vigor 01/04/2005. Inversión Cap. 7. Tratado de Libre Comercio para América del Norte. Entrada en vigor 01/01/1994, Inversión Cap. XI, Propiedad Intelectual Cap. XVII. Acuerdo entre el Gobierno de los Estados Unidos Mexicanos y el Gobierno de la República de Singapur para la Promoción y Protección Recíproca de las Inversiones. DOF, 1 de abril de 2011.
} 
favorable para el país receptor de la inversión.

Es decir, un inversionista que considere que su inversión ha sido afectada por el país receptor puede recurrir a la protección pactada en el TPP, y si en otros tratados se otorgara una mayor protección puede solicitar que se apliquen estas disposiciones que lo favorecen. Este principio se aplica igualmente si el tercer tratado también hubiera sido suscrito por el país del cual es residente el inversor y el país receptor. Podemos aclarar con un ejemplo: si el inversor AA de nacionalidad canadiense considera que una inversión definida y protegida como tal en este TPP ha sido afectada por el Estado mexicano puede recurrir al sistema de solución de controversias establecidos en este tratado pero solicitar que se aplique un cuerpo normativo integrado por las mejores disposiciones que lo beneficien establecidas en el TPP y en el TLCAN y en todos lo restantes Tratados de Libre Comercio celebrados por México que tengan capítulos protectores de la inversión extranjera y en los Bilaterales de Promoción y Protección de Inversiones. Si se tratara de un acto jurídico considerado como inversión protegida por el TLCAN y no por el TPP, podrá demandar con base en el TLCAN y realizar la misma petición de que se seleccione todas las opciones para poder seleccionar la que más lo beneficia.

Queda claro, entonces, que el principio de nación más favorecida es en la práctica "el principio del inversor extranjero más favorecido" en perjuicio de la "nación menos favorecida, receptora de la inversión".

Los capítulos de Propiedad Intelectual no contemplan disposiciones específicas sobre el Trato de Nación Más Favorecida, no se trata en este caso de la relación de una persona jurídica particular con un Estado Parte, sino del compromiso de todos los estados parte de ratificar los tratados que acordaron ratificar y de legislar conforme al compromiso contraído en el capítulo sobre propiedad intelectual; en este caso se aplica 


\section{ASPECTOS AMBIENTALES REgUlAdOS EN LOS RECIENTES TrATADOS DE LIBRE COMERCIO, CON ESPECIAL REFERENCIA AL TRATADO DE ASOCIACIÓN TRANS-PACífiCO (TPP)}

el principio de Trato Nacional, común a todos los tratados sobre propiedad intelectual desde la Convención de París.

La legislación que se establezca conforme al tratado favorecerá no sólo a las personas jurídicas residentes en los Países Partes del mismo, sino también a todas las personas jurídicas que soliciten un derecho de propiedad intelectual en el país, en nuestro caso en México. Por lo tanto, un residente de un país XX que no es Parte del TPP puede solicitar que se le otorgue una patente o que se le reconozca un derecho de autor sobre una creación que no es materia patentable ni obra protegida en su país; resultaría muy difícil imaginar disposiciones del sistema de propiedad intelectual de México, por ejemplo, que protegieran con diferentes estándares las mismas invenciones u obras según la residencia de la persona que lo solicita; y no lo podría hacer por cuanto en Tratados con vocación universal como la Convención de París y el Acuerdo ADPIC/OMC se reconoce el Principio de Trato Nacional.

Según lo establecido en el TPP, en el Acuerdo ADPIC (OMC) y en todos los capítulos sobre Propiedad Intelectual de Tratados Internacionales lo acordado en ellos son estándares mínimos, que pueden ser suplidos por estándares más elevados que amplíen la materia patentable o que otorguen una mayor protección, por lo cual, al igual que en el caso de las inversiones, de haber múltiples tratados que se refieran a la propiedad intelectual se deberá legislar al interior de los Países Partes conforme al coctel que resulte de todos las normas y principios que mayor protejan las obras e invenciones en la totalidad de los tratados suscritos por cada País Parte. En materia de patentes en México los nacionales nunca llegan a participar con más del $5 \%$ de las solicitudes (situación que se repite en todos los países en desarrollo) y más del $90 \%$ de los derechos de autor se remiten al exterior, lo cual puede dar una idea de los efectos perjudiciales de las interpretaciones a que hacemos referencia. 
En muchos casos, las políticas públicas protectoras del ambiente han derivado en demandas de los inversores extranjeros ante los tribunales arbitrales internacionales.

\section{Compromiso de Adherir a Tratados Internacionales de los Cuales los PAÍSES PARTES NO SEAN PARTE}

Múltiples capítulos del TPP se refieren a otros tratados internacionales; en el capítulo sobre Inversión establece los tratados internacionales por los cuales se puede optar para la aplicación del sistema de solución de diferencias, en el capítulo sobre Propiedad Intelectual los Países Partes se comprometen a adherir a múltiples tratados complementarios o modificatorios del Acuerdo ADPIC, sin embargo no se establece ningún compromiso de adhesión a Tratados en el capítulo sobre Medio Ambiente.

En materia de Propiedad Intelectual además del compromiso de adherir a los tratados clásicos que sustentan el núcleo normativo internacional de la materia: Convención de París, Convención de Berna, Acuerdo ADPIC de la OMC, los Países Partes se comprometen a adherir al Tratado de Cooperación en materia de Patentes (PCT), al Protocolo de Madrid; al Tratado de Budapest; al Tratado de Singapur; a UPOV 1991; al Tratado de la OMPI sobre Derecho de Autor (WCT), y al Tratado de la OMPI sobre Interpretación o Ejecución y Fonogramas (WPPT). De ellos, el que quizás ofrece mayores cuestionamientos en la doctrina jurídica y en los organismos no gubernamentales es el compromiso de países como México, Perú y Chile, actualmente adheridos a la Unión para la Protección de las nuevas Obtenciones Vegetales en su Acta 1978, de suscribir el Acta 1991, con disposiciones que pueden afectar a sus políticas ambientales y agrarias.

Por el contrario, no se establece ningún compromiso de adhesión a tratados internacionales en el capítulo ambiental, muchos de los cuales son relevantes para los 


\section{ASPECTOS AMBIENTALES REgUlAdOS EN LOS RECIENTES TrATADOS DE LIBRE COMERCIO, CON ESPECIAL REFERENCIA AL TRATADO DE ASOCIACIÓN TRANS-PACÍFICO (TPP)}

países mega diversos. En especial, de los tratados que guardan cierta relevancia en materia ambiental, no se establece el compromiso de adherir o ratificar el Convenio Sobre Diversidad Biológica y a sus Protocolos: de Cartagena sobre Bioseguridad de los Organismos Vivos Modificados Genéticamente y de Nagoya sobre Acceso a los Recursos Genéticos y Distribución de Beneficios; tampoco a la Convención de Naciones Unidas sobre Derecho del Mar (CONVEMAR), de importancia relevante para la regulación de la pesca en alta mar y en especial en zonas ajenas a las jurisdicciones nacionales y para la regulación de la bioprospección y utilización de recursos genéticos oceánicos en zonas fuera de las jurisdicciones nacionales.

En estos momentos no han firmado la CONVEMAR Estados Unidos de América y Perú. EUA no ha firmado la Convención sobre Diversidad Biológica (Río 1992) y por tanto no puede suscribir sus protocolos. Australia, Canadá, República de Singapur y Chile no han adherido al Protocolo de Cartagena de Bioseguridad de los Organismos Genéticamente Modificados y EUA, Canadá, Chile, Japón, República de Singapur no han adherido al Protocolo de Nagoya sobre Acceso a los Recursos Genéticos y Participación Justa y Equitativa en los Beneficios que se deriven de su Utilización (Protocolo de Nagoya).

El tema ambiental fue, junto al de la promoción y protección de la inversión extranjera, uno de los que más preocupó a la sociedad civil europea, temerosa de que las corporaciones norteamericanas, pero también las europeas, aprovecharan la negociación del TIIP para limitar los estándares de protección comunitaria del medio ambiente. Debido a ello, lograron que se dedicara un documento específico a las instrucciones que 
se entregarían a los negociadores y que éste se hiciera público. ${ }^{9}$ Ahora bien, pese a la fuerte presión de la sociedad civil europea y de legisladores comunitarios, no se propone a Estados Unidos que adhiera o ratifique los tratados ambientales, la instrucción se limita a proponer que se exprese que los Estados Unidos y la Unión Europea reconocen la existencia de los principales tratados internacionales ambiental. ${ }^{10}$ La timidez de la propuesta indica el conocimiento por parte de los negociadores de la Unión Europea de la firmeza con la que los Estados Unidos se resisten a adherir a los tratados multilaterales ambientales que pudieran afectar su participación en el mercado internacional de mercancías y servicios y la reiteración de su política de tener en alta consideración la problemática ambiental mundial pero reservándose el derecho a decidir de manera unilateral cuáles son las medidas que adoptará en la materia la principal potencia económica mundial.

\section{Aspectos Relevantes del CAPítulo sobre Medio Ambiente}

Las afectaciones directas al medio ambiente, a los derechos humanos y a los derechos sociales en general de las disposiciones mercantiles, financieras, y en especial las relacionadas con inversión y propiedad intelectual, por efecto de las disposiciones de

${ }^{9}$ EU Textual Proposal Trade and Sustainable Development. This Textual Proposal is the European Union's initial proposal for legal text on "Trade and Sustainable Development" in TTIP. It was tabled for discussion with the US in the negotiating round of 19 - 23 October 2015 and made public on 6 November 2015. The actual text in the final agreement will be a result of negotiations between the EU and US.

${ }^{10}$ EU Textual Proposal Trade and Sustainable Development. Section I - Trade and Sustainable Development - Overarching principles. Article 1.Context. ... 2. The Parties recall the Rio Declaration and the Agenda 21 on Environment and Development of 1992, the ILO Declaration on Fundamental Principles and Rights at Work of 1998 and its Follow-up, the Johannesburg Plan of Implementation on Sustainable Development of 2002, the Ministerial Declaration of the UN Economic and Social Council on Full Employment and Decent Work of 2006, the ILO Declaration on Social Justice for a Fair Globalization of 2008, the Outcome Document of the UN Conference on Sustainable Development of 2012 entitled "The Future We Want", and the outcome of the UN Summit on Sustainable Development of 2015 entitled "Transforming Our World: the 2030 Agenda for Sustainable Development". 


\section{ASPECTOS AMBIENTALES REgUlAdOS EN LOS RECIENTES TrATADOS DE LIBRE COMERCIO, CON ESPECIAL REFERENCIA AL TRATADO DE ASOCIACIÓN TRANS-PACífiCO (TPP)}

los Tratados de Libre Comercio ha sido parte importante de la literatura académica y de los medios de difusión especializados. Ello ha motivado que se inserten en su capitulado disposiciones específicas orientadas a garantizar estos derechos.

Un antecedente interesante en la materia se verificó en la negociación del Tratado de Libre Comercio para América del Norte; una vez finalizada la negociación y firmado por los ejecutivos de los tres países el Convenio, pero antes de su aprobación legislativa, se realizan elecciones presidenciales y de representantes en EUA. El candidato a presidente victorioso se había opuesto al tratado durante la campaña electoral por considerar que muchas corporaciones norteamericanas podrían trasladar a los otros países sus inversiones para aprovechar las menores exigencias de protección del medio ambiente y condiciones laborales más favorables, afectando el empleo de los trabajadores norteamericanos. Sin embargo, una vez que asumió la presidencia William Clinton evaluó que en su conjunto el TLCAN era favorable para EUA, por lo cual, a efectos de lograr su aprobación por un congreso que en su mayoría coincidía con sus críticas, presionó a Canadá y a México para que acepten modificaciones insertas en los denominados Acuerdos Paralelos sobre Medio Ambiente y sobre Aspectos Laborales, con sanciones económicas, no comerciales, para los casos de incumplimiento.

En el TPP se genera un avance respecto a los convenios precedentes sobre libre comercio e inversión suscritos por México, en tanto se incluye un capítulo específico en el cual los Países Partes asumen una serie de compromisos relacionados con temas ambientales con peculiaridades metodológicas que es conveniente analizar antes de comentar los temas específicos que aborda. 


\subsection{CONTENIDO DEL CAPÍTULO AMBIENTAL}

Las distinciones disciplinarias en el sistema jurídico tienen diversos objetivos, algunos de ellos prácticos como facilitar el proceso de enseñanza aprendizaje, otros jurisdiccionales y desde el punto de vista sustantivo, quizás el más relevante, la aplicación de ciertos principios específicos en su creación y aplicación. Ello hace que en muchos casos resulte importante precisar el contenido de las disciplinas jurídicas y quizás una de aquellas en la que ello destaca, por la relevancia de sus principios y por el reciente reconocimiento de su autonomía, sea el Derecho Ambiental y, de interés en nuestro estudio, el Derecho Ambiental Internacional. Baste ejemplificar con el intenso debate sobre si el cambio climático tenía o no su origen en el accionar humano, si la causal era antropocéntrica; si la respuesta era negativa su estudio correspondía a la ciencia de la naturaleza, si era positiva, como se demostró hasta el hartazgo, correspondía considerar los estudios de las ciencias naturales para el diseño de políticas públicas sustentadas en el derecho internacional y en los derechos positivos nacionales.

González Márquez define al Derecho Ambiental como la disciplina jurídica que tiene por objeto la tutela del bien jurídico "medio ambiente". ${ }^{11}$ El concepto de ambiente: "nos estamos refiriendo al medio circundante de la vida, a las características esenciales de la biósfera o esfera de la tierra donde habitan los seres vivos"12 es demasiado amplio como derivar de él el contenido del Derecho Ambiental, por lo cual la doctrina suele divergir y en muchos casos es influida por el contenido que recogen los regímenes positivos nacionales. ${ }^{13}$ Coinciden los autores, sin embargo, en que el Derecho Internacional Ambiental comprende como un núcleo sustantivo los temas considerados

\footnotetext{
${ }^{11}$ González Márquez, J. J. (2014). Teoría del Derecho Ambiental. Volumen I: Los fundamentos jurídicos de la sostenibilidad (p. 75). México: Instituto Mexicano de Investigaciones en Derecho Ambiental.

${ }^{12}$ Martín Mateo, R. (2003). Manual de Derecho Ambiental (p. 21). España: Thomson.

${ }^{13}$ Así lo hace Lorenzetti, R. (2008). Teoría del Derecho Ambiental (p. 12 y ss.). Buenos Aires: La Ley.
} 


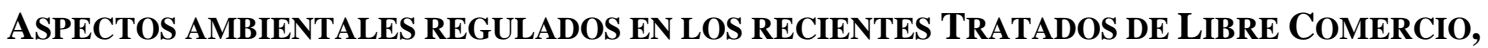 CON ESPECIAL REFERENCIA AL TRATADO DE ASOCIACIÓN TRANS-PACífiCO (TPP)}

por las declaraciones y las convenciones aprobadas en la Cumbre de la Tierra que tuviera lugar en Rio de Janeiro en 1992 y en su continuación en Johannesburgo (2002) y Río (2012), en especial la preservación de la biodiversidad y, relacionada con la misma la bioseguridad y la regulación del acceso; la conservación de las condiciones naturales que permiten garantizar la preservación de la naturaleza viva para la actual y para las futuras generaciones. En este sentido José Juste Ruiz recoge los términos de la Corte Internacional de Justicia en su opinión consultiva sobre la legalidad del empleo de armas nucleares de 6 de julio de 1966: "El medio ambiente no es una abstracción sino el espacio en el que viven los seres humanos y del que depende la calidad de su vida y su salud, inclusive de las generaciones futuras". ${ }^{14}$

El contenido del capítulo 20 del TPP sobre Medio Ambiente es bastante restringido; si bien comienza definiendo a la Ley Ambiental en sentido muy amplio como aquellas leyes, decretos de una parte, incluyendo las que implementen obligaciones derivadas de un acuerdo multilateral, cuyo propósito principal sea la protección del medio ambiente, acto seguido realiza una enumeración muy limitada:

“a) la prevención, el abatimiento o el control de: una fuga, descarga o emisión de contaminantes ambientales;

b) el control de químicos, sustancias, materiales o desechos ambientalmente peligrosos o tóxicos, y la diseminación de información relacionada con ello; o

c) la protección de la flora y fauna silvestres, incluso especies en peligro de extinción, su hábitat y las áreas naturales especialmente protegidas. ",15

\footnotetext{
14 Juste Ruiz, J. y Castillo Daudí, M. (2014). La Protección del Medio Ambiente en el Ámbito Internacional y en la Unión Europea (p. 11). Valencia: Tirant Blanch.

${ }^{15} \mathrm{TPP}$, art. 20.1.
} 
Y acto seguido excluye las leyes o reglamentos cuyo propósito principal sea "gestionar la subsistencia o la cosecha aborigen de recursos naturales" o aquellas relacionadas con la salud e higiene de los trabajadores.

Las disposiciones sustantivas del capítulo son muy generales y ambiguas, son una larga enumeración sobre la importancia que las partes reconocen a problemas ambientales genéricos, sin compromisos concretos. Un claro ejemplo es la disposición que dice que "las partes reconocen que es inapropiado alentar el comercio o la inversión mediante el debilitamiento o la reducción de la protección otorgada en sus respectivas leyes ambientales". ${ }^{16}$ Dice que las partes reconocen el papel importante de los acuerdos multilaterales sobre medio ambiente pero no establece el compromiso de adherir a ninguno de ellos, como sí lo hace en el capítulo sobre Propiedad Intelectual. Por último, dedica fracciones específicas a la Protección del Medio Marino de la Contaminación por Buques, a la Pesca de Captura Marina, a la Protección de la Capa de Ozono, a la relación del Comercio con la Biodiversidad, a las Especies Exóticas Invasoras, a las Bajas Emisiones.

La principal características de los puntos específicos que se desarrollan es que no se establecen compromisos concretos identificables con precisión, medibles o cuantificables; son meros reconocimientos de su importancia y promesas generales de contenidos que las partes consideran importante regular.

Pese a estos aspectos no satisfactorios, considero que el contenido de este capítulo es importante en tanto implica aceptar que los principios crematísticos que rigen el libre comercio, el flujo internacional de capitales y los monopolios derivados de la propiedad intelectual no deben afectar el medio ambiente y se puede considerar un

${ }^{16}$ TPP, art. 20.4. 


\section{ASPECTOS AMBIENTALES REgUlAdOS EN LOS RECIENTES TrATADOS DE LIBRE COMERCIO, CON ESPECIAL REFERENCIA AL TRATADO DE ASOCIACIÓN TRANS-PACífiCO (TPP)}

primer paso para una reglamentación más precisa susceptible de aplicación coercible. Un avance concreto de los derechos ambientales reconocidos en este capítulo reside en la posibilidad de poder argumentar limitaciones al libre flujo de mercancías y servicios para evitar daños a los bienes ambientales reconocidos.

\subsection{Protección de la Diversidad Biológica, ReCursos Genéticos}

Las partes reconocen en este capítulo la importancia de la diversidad biológica, se comprometen al uso sostenible de los recursos y a proteger los conocimientos tradicionales que contribuyan a conservarla. Acto seguido se refiere a un punto de interés primordial para los países industrializados con mayor capacidad en materia de biología molecular y biotecnología, el derecho de acceso a los recursos genéticos. Ahora bien, la Convención sobre Diversidad Biológica y el Protocolo de Nagoya regulan el acceso a los recursos y a los conocimientos tradicionales a ellos vinculados reconociendo el derecho soberano de los estados sobre los mismos, así como la obligación de los países partes de solicitar el acuerdo fundamentado previo y concertar la justa distribución de utilidades con los Estados y las comunidades locales si así correspondiere (no se logró en la Convención incorporar el compromiso de los países partes de exigir la genealogía al recibir una solicitud de derecho de propiedad intelectual sobre un producto cuyo origen fuera un organismo vivo); si hubiera una preocupación seria sobre este aspecto del Derecho Ambiental hubiera bastado con que los países partes se comprometieran a adherir a estas Convenciones. Por el contrario, se establece en una redacción muy precisa los países partes reconocen "la importancia de facilitar el acceso a los recursos genéticos dentro de sus respectivas jurisdicciones" cuando el acceso sea acordado incluyendo la distribución de beneficios. Pero los Países Partes no se comprometen a requerir el Acuerdo Fundamentado Previo y a suscribir un acuerdo 
sobre distribución de utilidades, sino que sólo "reconocen que algunas Partes (los) requieren a través de medidas nacionales". ${ }^{17}$

\subsection{BIOSEguridad de los ORganismos Vivos Modificados GenétiCAMENTE}

La siembra y comercialización de granos y cereales modificados genéticamente se concentra en un número reducido de países que además de abastecer el consumo interno exportan un elevado porcentual de sus cosechas; EUA con 73.1 millones de hectáreas sembradas con transgénicos y Canadá con 11.6 millones de hectáreas, representan el $46.7 \%$ de la superficie total sembrada en el mundo con transgénicos, Australia participa con una superficie menor, 500 mil hectáreas; ninguno de los tres, miembros del TPP, han suscrito el Protocolo de Cartagena sobre Bioseguridad de los Organismos Vivos Modificados del Convenio de Diversidad Biológica; EUA tampoco es miembro del CDB.

Es por la presión de estos países, con la colaboración de Chile (que tampoco ha suscrito el Protocolo), que se excluye la relación del comercio internacional de granos y cereales con la regulación internacional de la bioseguridad de los OGM del capítulo ambiental y se lo traslada al Capítulo 2 sobre Trato Nacional y Acceso de Bienes al Mercado, en la Sección C - Agricultura. ${ }^{18}$ Ahora bien, no se trata sólo de un problema teórico metodológico que modifica la opinión de la doctrina y de la legislación positiva,

\footnotetext{
${ }^{17}$ Ver TPP, art. 20.13 Comercio y Biodiversidad.

18 Durante las negociaciones del Protocolo de Cartagena se conformó un grupo de seis países que se oponían a la regulación de la bioseguridad de los OGM, salvo los que fueran sustancialmente diferente a los naturales, conocido como Grupo de Miami, integrado por EUA (que no podía ser parte activa en la negociación por cuanto no era parte del CDB), Canadá, Australia, Chile, Uruguay y Argentina. Un tema sustantivo en el debate fue la inserción del denominado principio precautorio o principio de cautela en el Protocolo. Sobre el debate en el proceso de negociación del protocolo ver: Pérez Miranda, R. (2002). Biotecnología, Sociedad y Derecho. México: Miguel Ángel Porrúa - UAM. Larach, M. A. (2001). El Comercio de los Productos Transgénicos: el estado del debate internacional. Revista de la CEPAL, (75), 211 y ss.
} 


\section{ASPECTOS AMBIENTALES REgUlados EN LOS RECIENTES Tratados DE LIBRE COMERCIO, CON ESPECIAL REFERENCIA AL TRATADO DE ASOCIACIÓN TRANS-PACÍFICO (TPP)}

casi unánime, que ubica en el derecho ambiental, y en la legislación ambiental, respectivamente, la regulación de la bioseguridad de los organismos vivos modificados genéticamente, sino de los efectos diferentes que surgen de su ubicación en áreas diversas del Derecho Internacional.

En efecto, en el comercio internacional, las evaluaciones de riesgo que permiten autorizar o prohibir la importación de granos, cereales y alimentos de origen animal están sujetas a normas diferentes si se trata de organismos vivos modificados genéticamente o productos vegetales o animales naturales. Una diferencia sustancial en esta evaluación deriva de la aplicación del principio precautorio, del reconocimiento del principio precautorio o de cautela en el Derecho Internacional; este principio es reconocido en el Derecho Internacional Ambiental, en especial en el Protocolo de Cartagena (CDB), pero es cuestionado e incluso rechazado, por el Acuerdo sobre Aplicación de Medidas Sanitarias y Fitosanitarias (OMC).

Es decir, la aplicación de los principios del Derecho Internacional Ambiental permite un ejercicio más pleno de la soberanía estatal para poder impedir la importación de bienes que puedan afectar el medio ambiente y la salud de los habitantes de un país. Es interesante a este respecto partes de un dictamen del Órgano de Apelación de la OMC:

“... 121. La argumentación básica de las Comunidades Europeas es que el principio de cautela es o se ha convertido en "una norma consuetudinaria general del derecho internacional" o al menos "en un principio general del derecho"... Los Estados Unidos no consideran que el "principio de cautela" represente el derecho internacional consuetudinario y sugieren que se trata más de un enfoque que de un principio”. El Canadá también es de la opinión de que 
el principio de cautela aún no ha sido incorporado al corpus del derecho internacional público....

Y decide el Órgano de Apelación:

123. La condición jurídica del principio de cautela en el derecho internacional sigue siendo objeto de debate entre los académicos, los profesionales del derecho, los órganos normativos y los jueces. Algunos consideran que el principio de cautela se ha cristalizado en un principio general del derecho medioambiental internacional consuetudinario. El hecho de que haya sido aceptado ampliamente por los Miembros como un principio de derecho internacional general o consuetudinario parece menos claro. ",19

Esta interpretación no ha cambiado sustancialmente en los últimos años, y de allí la importancia de la ubicación subdisciplinaria de la regulación del comercio internacional de Organismos Vivos Modificados Genéticamente.

Los motivos de la metodología de exposición elegida quedan claros, por otra parte, al leer el contenido de lo dispuesto en el Artículo 2.29: Comercio de productos de la biotecnología moderna, en el que no se hace ninguna referencia al Protocolo de Cartagena ni al derecho soberano de las partes para regular las importaciones de organismos vivos modificados según sus disposiciones sobre bioseguridad, por el contrario, dice que reconoce el derecho de las partes a adoptar "medidas conforme a sus derechos y obligaciones derivados de los acuerdos de la OMC u otras disposiciones de este Tratado"; a posteriori reconoce el derecho de las partes a regular los productos de la

\footnotetext{
${ }^{19}$ Organización Mundial Del Comercio. Órgano de Apelación. WT/ DS26/AB/R - WT/DS48/AB/R 16 de enero de 1998.
} 


\section{ASPECTOS AMBIENTALES REgUlAdOS EN LOS RECIENTES TrATADOS DE LIBRE COMERCIO, CON ESPECIAL REFERENCIA AL TRATADO DE ASOCIACIÓN TRANS-PACífiCO (TPP)}

biotecnología moderna, pero "dentro de su territorio", a contrario sensu reitera que no lo podrá hacer en materia de comercio exterior. Es decir, los conflictos que se pudieran presentar relacionados con Organismos Vivos Modificados Genéticamente se resolverán conforme a las reglas de solución de diferencias del TPP o de la OMC pero aplicando las normas del Acuerdo sobre Agricultura (OMC) y del Acuerdo sobre la aplicación de Medidas Sanitarias y Fitosanitarias (OMC).

Es más detallado y específico el artículo sobre biotecnología moderna cuando regula los denominados "niveles bajos", es decir, para que no se generen problemas a la importación de mercancías en las cuales pudiera haber "una presencia inadvertida" de productos que al menos en el país interesado no estuviera autorizada su importación. A estos posibles obstáculos se dedica la mayor extensión del artículo que comentamos.

\subsection{MEDIO AMBIENTE E INVERSIÓN EXTRANJERA}

Las tradicionales disposiciones sobre protección de las inversiones permitieron que se abusara de ellas y se impidiera a los estados que habían suscrito los tratados bilaterales de protección de inversiones o que habían incorporado un capítulo sobre protección de inversiones en tratados de libre comercio, promover políticas públicas protectoras de la salud de sus habitantes o del medio ambiente. Un caso destacado fue la demanda de la empresa Philips Morris contra los gobiernos de Australia y de Uruguay cuando éstos impulsaron políticas para disuadir el consumo de tabaco. ${ }^{20} \mathrm{O}$ la demanda presentada contra el gobierno alemán cuando redujo sustancialmente su programa de producción de energía nuclear con motivo del Tsunami que afecto una central nuclear

\footnotetext{
${ }^{20}$ Philip Morris Asia Limited v. la Mancomunidad de Australia, Notificación de Arbitraje, Reglamento de Arbitraje de la CNUDMI (2011). http://www.iisd.org/itn/2011/07/12/philip-morris-v-uruguay-willinvestor-state-arbitration-send-restrictions-on-tobacco- marketing-up-in-smoke.
} 
moderna en Japón. Es así que en tratados suscritos por la Unión Europea con terceros países, se incluyeron disposiciones que excluían la posibilidad de que estas medidas nacionales se pudieran considerar una expropiación indirecta. Así lo dispone el Tratado de Libre Comercio celebrado entre la Unión Europea y Canadá que establece que las disposiciones de una parte que tiene por objetivo proteger intereses públicos como la salud, la seguridad y el medio ambiente "no constituyen expropiación indirecta". ${ }^{21}$ Una disposición similar se inserta en el TPP que se refiere a la posibilidad de que un país parte exija que las inversiones se realicen de una manera sensible al medio ambiente. ${ }^{22}$ En el Anexo 9 -b sobre Expropiación se incluye una disposición igual a la del Tratado CETA, en tanto se expresa que:

Salvo en circunstancias excepcionales, no constituyen expropiaciones indirectas los actos regulatorios no discriminatorios de una Parte que son diseñados y aplicados para proteger objetivos legítimos de bienestar público, tales como la salud pública, la seguridad y el medioambiente. ${ }^{23}$

La similitud de las disposiciones establecidas en el CETA y en el TPP sugiere que el texto de éste fue propuesto por Canadá:

\begin{tabular}{|l|l|}
\hline CETA - 10. EXPROPRIATION. & TPP-EXPROPRIATRION - ANNEX 9 \\
ANNEX .11 & - B EXPROPRIATION \\
\hline 3...non-discriminatory measures of a & 3.B Non-discriminatory regulatory actions \\
Party that are designed and applied to & by a Party that are designed and applied to \\
\hline
\end{tabular}

\footnotetext{
${ }^{21}$ Consolidated CETA Text.Published on 26 September 2014.10. Investment. Anex X.11.

${ }^{22}$ TPP Capítulo de Inversiones, art. 9.15

${ }^{23}$ TPP. Cap. Sobre Inversión. Anexo I, párrafo 3. (b).
} 
ASPECTOS AMBIENTALES REgUlados EN LOS RECIENTES TRATAdOS DE LibRE COMERCiO, CON ESPECIAL REFERENCIA AL TRATADO DE ASOCIACIÓN TRANS-PACífiCO (TPP)

protect legitimate public welfare

objectives, such as health, safety and the

environment, do not constitute indirect

expropriations. protect legitimate public welfare objetives,

such as public health, safety and the

environment, do not constitute indirect

expropriations, except in rare

circumstances.

Sin embargo, esta disposición del CETA no se originó en Canadá sino en la decisión de la Unión Europea de cambiar los lineamientos tradicionales de los tratados bilaterales de protección de inversiones y de los capítulos sobre inversión de los tratados de libre comercio, en especial por cuanto se estaban, y están, negociando tratados con países desarrollados que tienen importantes inversiones en la Unión Europea: Canadá (ya firmado) y Estados Unidos (en negociación). ${ }^{24}$

\subsection{Medio Ambiente Y Recursos Genéticos Oceánicos Fuera de las JURISDICCIONES NACIONALES}

La referencia a los recursos genéticos marinos se limita a los alimenticios, es decir a la preservación de los recursos pesqueros y a su manejo sostenible; en especial las partes se comprometen a evitar "la sobrepesca y la sobrecapacidad", reducir la captura incidental de especies no objetivo y juveniles y a promover la recuperación de poblaciones sobreexplotadas; se comprometen por otra parte a evitar, o reducir, las subvenciones a la pesca y a los buques pesqueros. Sin embargo, no se establecen normas que permitan traducir en magnitudes controlables las propuestas generales, si

\footnotetext{
${ }^{24}$ European Commission. Protección de la inversión y solución de controversias entre inversor y Estado en los acuerdos de la UE Noviembre de 2013
} 
bien se hace referencia a los acuerdos internacionales vigentes en la materia, que los países en desarrollo y la doctrina ambiental consideran claramente ineficientes y que en la práctica son controlados por los países con una mayor infraestructura para la pesca en alta mar.

Por último, no se hace ninguna referencia a las negociaciones impulsadas por las Naciones Unidas para lograr una Convención Internacional Vinculante sobre recursos genéticos marinos en zonas fuera de las jurisdicciones nacionales por considerarlos bienes comunes patrimonio de la humanidad. Estados Unidos, Japón (y de los países que no pertenecen al TPP: Francia, Gran Bretaña, Alemania) son de los pocos países que disponen de infraestructura tecnológica para la realización de bioprospección y colecta de estos recursos, en especial los que se encuentran en las zonas más profundas, se oponen a las principales propuestas actuales de regulación, pero resulta contradictorio que países que las impulsan como son la mayoría de los que han suscrito el TPP no hayan hecho hincapié respecto a este tema.

\subsection{Agrobiotecnología, Medio Ambiente y Propiedad Intelectual.}

\section{VEGETALES Y ANIMALES}

Uno de los temas más debatidos durante la negociación del TPP ha sido el de la Propiedad Intelectual, lo cual en gran medida fue posible por filtraciones que permitieron conocer las propuestas de los países partes en el debate, en especial la de EUA; lo relevante de su contenido exige una investigación y un ensayo especial. Sin 


\section{ASPECTOS AMBIENTALES REgUlados EN LOS RECIENTES Tratados DE LIBRE COMERCIO, CON ESPECIAL REFERENCIA AL TRATADO DE ASOCIACIÓN TRANS-PACífiCO (TPP)}

embargo, es conveniente hacer una breve referencia a algunos aspectos vinculados al medio ambiente. ${ }^{25}$

El TPP precisa con claridad que las partes deberán otorgar derecho de patente a todas las invenciones de producto o proceso nuevas, que muestren actividad inventiva y sean susceptible de explotación industrial, en línea con el Acuerdo sobre Aspectos de la Propiedad intelectual vinculada al Comercio (ADPIC/OMC); sin embargo, a diferencia de otros tratados, inclusive de los más recientes suscritos por EUA con Colombia y Perú, no se dice de manera expresa que los Países Partes pueden acogerse a las excepciones de patentabilidad establecidas en el art. 27 inc. 3 del Acuerdo ADPIC y establece posibilidades de excepción mucho más limitadas, ampliando así de manera no expresa la materia patentable, en especial en el tema que en estos párrafos nos ocupan.

La redacción sobre las excepciones al principio de generalidad de la patentabilidad de todas las invenciones es muy precisa, haciendo una distinción entre animales y plantas, distinción que evidencia el objetivo crematístico de la disposición, que no guarda relación con la teoría y con los principios de la propiedad intelectual; es decir, se establece un régimen específico para los vegetales atendiendo a los intereses de las corporaciones internacionales agrobiotecnológicas y en desmedro de los países en desarrollo y mega diversos.

Expresa el TPP que se puede prohibir el patentamiento de animales, también se puede excluir el patentamiento de plantas pero se debe otorgar patentes a las invenciones derivadas de plantas; disposición poco clara que será objeto de debate en su interpretación y traslado a las legislaciones nacionales.

${ }^{25}$ TPP. Art. 18 Propiedad Intelectual. 
Artículo 18.37: Materia Patentable ... 3. ... Una Parte puede excluir también de patentabilidad: ... (b) animales que no sean microorganismos, y procesos esencialmente biológicos para la producción de plantas o animales, que no sean procesos no biológicos o microbiológicos. 4. Una Parte también puede excluir de patentabilidad plantas que no sean microorganismos. Sin embargo, de conformidad con el párrafo 1 y con sujeción al párrafo 3, cada Parte confirma que las patentes estarán disponibles al menos para invenciones derivadas de plantas.

En principio, los Países Partes pueden decidir que no se permitirá patentar plantas, aunque hayan sido modificadas genéticamente, por ejemplo no se puede patentar la planta de maíz con Bt o la soja de Monsanto con resistencia al glifosato y con protección a los lepidópteros, tampoco un vegetal transgénico en general; esta prohibición es generalizada, si bien EUA ha insistido en introducir la posibilidad de otorgar estas patentes de manera indirecta en otros tratados, incluyendo una disposición que compromete a los países a realizar esfuerzos para legislar a favor de otorgar patentes a las plantas $\mathrm{y}$, en caso de que se autorice el patentamiento, a no derogar esa norma. ${ }^{26}$ Ello no ofrece ningún obstáculo por cuanto los mecanismos de protección previstos son muchos más amplios e incluyen las plantas, según se puede describir sintéticamente

Una semilla, un esqueje, no es una planta; un gene o fragmento de gene de una especie o variedad de planta, tampoco es una planta; en consecuencia, los países partes deberán disponer el otorgamiento de patentes para material genético que se pueda considerar una invención en tanto no sea una planta: fragmentos de genes modificados

\footnotetext{
${ }^{26}$ Ver Tratado de Libre Comercio de EUA con Colombia.
} 


\section{ASPECTOS AMBIENTALES REgUlados EN LOS RECIENTES Tratados DE LIBRE COMERCIO, CON ESPECIAL REFERENCIA AL TRATADO DE ASOCIACIÓN TRANS-PACífiCO (TPP)}

genéticamente, genes modificados, semillas, esquejes o cualesquier material de propagación (se originan en las plantas, pero no son plantas).

Ahora bien, si se otorga una patente a un gene modificado todo material que contenga ese gene, sea en un grano, semilla, material de propagación o en la misma planta, y que no se haya originado en una adquisición al titular de la patente o a quién él haya autorizado para su comercialización, puede ser objeto de un reclamo por violación de derechos de propiedad industrial. Es decir, no se otorga patente a la planta de maíz modificada genéticamente, pero en tanto tiene un gene modificado por biotecnología la planta está protegida y se podrá demandar a quién la sembró. En estos casos, la violación es objetiva, el titular de la patente no debe probar ninguna otra circunstancia dolosa o culposa, basta con probar que la planta tiene el gene protegido. ${ }^{27}$ Por otra parte, el titular de la patente sobre el gene modificado, o sobre la semilla, podrá perseguir a quienes truequen o comercien con la misma, onerosa o gratuitamente, y salvo disposición expresa de la legislación que recoja el compromiso contraído en el tratado, también a quienes utilicen el producto de su cosecha para volver a sembrar en su fundo.

Además de lo expuesto en los párrafos precedentes, las plantas se podrán proteger como nueva variedad vegetal, de tal manera que el agricultor no sólo deberá pagar un plus por sembrar una semilla patentada o con un gene patentado, sino que además deberá pagar regalías por cuanto ese gene patentado se encuentra en una planta registrada como una nueva obtención vegetal.

La disposición sobre patentabilidad de las invenciones que se originan en una planta se articula con el compromiso contraído por los Estados Partes de adherir al Acta

\footnotetext{
${ }^{27}$ Ver: SupremeCourt of theUnitedStates. Bowman v. Monsanto Co et Al. May 13, 2013.
} 
de 1991 de la Unión para la Protección de nuevas Obtenciones Vegetales (UPOV 1991) a que se hiciera referencia supra. Es esta una propuesta tradicional de las grandes corporaciones biotecnológicas en tanto esta versión autoriza la doble protección con patente y derechos de obtentor. Se cubre así una posible impugnación que argumentara que al patentarse una semilla o un gene se estaría patentando indirectamente la planta y al registrarse una variedad que se originara en el gene o en la semilla se estaría otorgando una doble protección al mismo producto. La adhesión a UPOV 1991 permitirá la doble protección y, en razón de ello, el derecho a exigir el pago de dobles regalías y, además, a impedir el uso legítimo de parte del producto de la cosecha para volver a sembrar en el mismo fundo, o para intercambiar semillas con otros campesinos o agricultores, estimulando la generación de nuevas variedades.

Como expusiéramos, será motivo de debate doctrinario y legislativo la obligación de otorgar patentes a invenciones derivadas de plantas; una posibilidad es que se consideren comprendidos fármacos y demás productos biotecnológicos, sin tener que informar sobre su genealogía, es decir, sin tener que demostrar el origen legítimo del recurso genético ni de que lo obtuvieron con participación de las autoridades gubernamentales del país de origen, previo otorgamiento del permiso fundamentado previo y de contraer el compromiso expreso de distribución equitativa de beneficios.

\section{Algunas Conclusiones}

Los Tratados de Libre Comercio e Inversión denominados Transpacífico, Transatlántico y CETA, por el ámbito geográfico y por la importancia económica de los países concernidos, están diseñando líneas claras de Derecho Económico Internacional, relativamente homogéneas, orientadas a servir de bases en una futura modificación de aspectos normativos sustantivos de la Organización Mundial del Comercio y de los 


\section{ASPECTOS AMBIENTALES REgUlAdOS EN LOS RECIENTES TrATADOS DE LIBRE COMERCIO, CON ESPECIAL REFERENCIA AL TRATADO DE ASOCIACIÓN TRANS-PACÍFICO (TPP)}

Acuerdos que son de adopción obligatoria por parte de los países miembros. Estos lineamientos son producto de propuestas de los países industrializados en convenios concertados inter se y en otros celebrados con países en desarrollo, los cuales tienen pocas posibilidades de lograr que se reconozcan sus intereses económicos, financieros $\mathrm{y}$, en especial, sus necesidades sociales.

Una muestra clara del peso negociador de EUA es que, en materia de Propiedad Intelectual, los Países Partes del TPP se comprometen a adherir y ratificar un núcleo de tratados internacionales a los que ya pertenece EUA y que contemplan las normas sustantivas y procedimentales eficientes según su concepción en la materia. Por el contrario, en materia de Derechos Ambientales, ni en el TPP ni en las Directivas entregadas a los negociadores de la Unión Europea para negociar el tratado de libre comercio e inversión con EUA se exige a EUA que adhiera o ratifique convenios a los que pertenecen todos los países de la Unión Europea y los restantes miembros del TPP, como la Convención sobre Diversidad Biológica, o a la que adhieren la mayoría, como la CONVEMAR.

Derivado de las conclusiones anteriores resulta un capítulo sin compromisos concretos, y sí con algunos resultados perjudiciales como la aceptación de los miembros del TPP de que el comercio de organismos vivos modificados genéticamente se debe regular en el ámbito de la Agricultura, sin considerar al Protocolo de Cartagena sobre Seguridad de los Organismos Vivos Modificados y que no se establezcan normas mínimas que regulen el acceso a los recursos genéticos.

Otro aspecto negativo se relaciona con la Agrobiotecnología vinculada al Derecho Ambiental y a la Propiedad Intelectual, en tanto los países se comprometen a adherir al ACTA 1991 de UPOV y a otorgar patente a invenciones derivadas de las 
plantas, como pueden ser los genes modificados de las semillas o las mismas semillas y esquejes.

\section{REFERENCIAS BIBLIOGRÁFICAS}

Acuerdo entre el Gobierno de los Estados Unidos Mexicanos y el Gobierno de Australia para la Promoción y Protección Recíproca de las Inversiones.

Acuerdo para el Fortalecimiento de la Asociación Económica entre los Estados Unidos Mexicanos y el Japón; entrada en vigor 01/04/2005.

Becerra Ramírez, M. (2013). El control de la aplicación del derecho internacional. En el marco del Estado de derecho. México: Editorial Universidad Nacional Autónoma de México. Instituto de InvestigacionesJurídicas.

Consolidated CETA Text, Publishedon 26 September 2014.

Council of the European Union.Directives for the negotiation on the Transatlantic Trade and Investment Partnership between the European Union and the United States of America. Brussels, 9 October 2014.

EU Textual Proposal Trade and Sustainable Development.European Union's initial proposal for legal text on "Trade and Sustainable Development" in TTIP.Octubre 2015.

EuropeanCommission. Protección de la inversión y solución de controversias entre inversor y Estado en los acuerdos de la UE. Noviembre de 2013.

González Márquez, J. J. (2014). Teoría del Derecho Ambiental. Volumen I: Los fundamentos jurídicos de la sostenibilidad. México: Editorial Instituto Mexicano de Investigaciones en Derecho Ambiental.

Juste Ruiz, J. y Castillo Daudí, M. (2014). La Protección del Medio Ambiente en el Ámbito Internacional y en la Unión Europea. Valencia: Editorial Tirant Blanch. 
ASPECTOS AMBIENTALES REgUlados EN LOS RECIENTES Tratados DE LibRE COMERCiO, CON ESPECIAL REFERENCIA AL TRATADO DE ASOCIACIÓN TRANS-PACífiCO (TPP)

Larach, M. A. (2001). El Comercio de los Productos Transgénicos: el estado del debate internacional. Revista de la CEPAL, (75).

Lorenzetti, R. L. (2008). Teoría del Derecho Ambiental. Buenos Aires: Editorial La Ley.

Martín Mateo, R. (2003). Manual de Derecho Ambiental. España: Editorial Thomson.

Organización Mundial del Comercio. Órgano de Apelación. WT/ DS26/AB/R WT/DS48/AB/R 16 de enero de 1998.

Pérez Miranda, R. (2002). Biotecnología, Sociedad y Derecho. México: Editorial Miguel Ángel Porrúa - UAM.

Tratado de Libre Comercio de EUA con Colombia.

Tratado de Libre Comercio entre la República de Chile y los Estados Unidos Mexicanos. Vigencia indefinida. Entrada en vigor: 01/08/1999.

Tratado de Libre Comercio para América del Norte. Entrada en vigor 01/01/1994. 